\title{
A (IR) RENUNCIABILIDADE DO DIREITO DE USO DE IMAGEM DO JOGADOR DE FUTEBOL
}

\author{
Fábio Dias da Silva ${ }^{1}$, Daniel Merizio Casati ${ }^{2}$ \\ ${ }^{1}$ Universidade Estadual de Londrina - UEL, Curso de Especialização em Direito Previdenciário. ${ }^{2}$ Universidade do Oeste \\ Paulista - UNOESTE, Curso de Direito.E-mail:dm_casati@hotmail.com; fabiodiasilva@gmail.com.
}

\section{RESUMO}

Pelo presente estudo foi possível trazer em cheque a possibilidade de que se tenha a renuncia dos direitos do uso de imagem do jogador de futebol, ainda mais presente com os avanços tecnológicos que a exposição da figura do atleta ocorre de forma mais corriqueira. Nesse parâmetro, o objetivo cingiu-se em estabelecer bases tanto legais quanto doutrinárias para que se tenha a relativização do direito de imagem, vezes que o jogador, quando contratado em um clube, ou até para fins de propaganda, necessita da tutela de seu direito de imagem, sob pena de ter uma violação em seu direito de personalidade. Consoante à disposição do trabalho, houve a concreta delineação de que é possível a renuncia somente o direito ao uso da imagem, e não com relação ao direito de personalidade propriamente dito, haja vista que esse é irrenunciável, inerente à condição do ser humano, relevando-se que a verba adquirida é de natureza indenizatória e de um modo a compor a violação tida.

Palavras-chave: Imagem. Personalidade. Relativização. Renúncia. Indenizatória.

\section{A (IR) WAIVER OF THE RIGHT TO USE THE IMAGE OF THE FOOTBALL PLAYER}

\begin{abstract}
By the present study it was possible to bring in check the possibility of having the renunciation of the rights of the use of image of the soccer player, even more present with the technological advances that the exhibition of the figure of the athlete occurs in a more ordinary way. In this parameter, the objective was to establish both legal and doctrinal bases for the relativization of image rights, times when the player, when hired in a club, or even for advertising purposes, needs the protection of his right of image, under penalty of having a violation in his right of personality. According to the disposition of the work, there was the concrete delineation that it is possible to renounce only the right to use the image, and not with regard to the right of personality itself, since it is inalienable, inherent in the condition of the human being, that the amount acquired is of an indemnity nature and in a way to compose the violation.
\end{abstract}

Keywords: Image. Personality. Relativization. Renounce. Indemnification. 


\section{INTRODUÇÃO}

Com a instituição dos direitos denominados de personalidade advém grande controvérsia jurídica se é possível a sua relativização ou até sua renúncia, tendo em vista que com a atualidade e evolução jurídica e social há cada vez mais abertura do leque de exceções para que esses direitos não sejam ferreamente protegidos.

E sob esse prisma que a renúncia, ou não, do direito de imagem do atleta de futebol entra em questão, vezes que esse é usualmente alvo de propagandas e até de imagens divulgadas, sendo que se não houver a sua expressa concordância haverá uma consequente violação a esse direito de personalidade, inerente à própria pessoa.

Por esse ponto, a partir do método dedutivo, pela utilização do panorama geral dos direitos de personalidade para partir ao direito de imagem propriamente dito do jogador de futebol foi trazida a questão da sua renuncia e o direito de ser indenizado quando tiver a utilização desse direito de uso.

Assim sendo, o objetivo desse estudo foi buscar explanar a possibilidade de renuncia do direito de uso da imagem, e não propriamente o direito de imagem, relacionado aos jogadores de futebol, embasado no ordenamento jurídico pátrio.

\section{DISCUSSÃO}

\section{DIREITOS DE PERSONALIDADE: CONCEITO E CARACTERÍSTICAS}

A princípio, denotamos que os direitos de personalidade detiveram de grande influência da dignidade da pessoa humana, conceito aberto e amplo trazido pela Constituição da República Federativa do Brasil de 1.988 como um de seus fundamentos a ser resguardado e aplicado não somente ao texto constitucional como a todo ordenamento jurídico.

Nesse parâmetro, os direitos de personalidade servem para resguardar os direitos relacionados à própria sobrevivência e existência de uma forma digna do ser humano, tendo em vista que é esse o titular dessa gama de direitos.

Elimar Szaniawski (2005, p. 143) preconiza que a partir da dignidade da pessoa humana, como uma cláusula geral de tutela da personalidade do ser humano, transformaram-se os direitos de personalidade como legítimos preceitos para a realização da vida social em relações com particulares, deixando a concepção de que os princípios constitucionais se destinavam somente à proteção do indivíduo contra atos do Estado.

Por essa forma se demonstra que os direitos de personalidade foram primeiramente trazidos com a Constituinte de 1988, refletindo o caráter que a dignidade da pessoa humana deve ter para com o ordenamento jurídico pátrio, qual seja, trazer um tratamento digno para todo e qualquer indivíduo.

Para fins de conceituação do que se tratam os direitos de personalidade Pablo Stolze Gagliano e Rodolfo Pamplona Filho (2014, p. 186) os definem como "[...] aqueles que têm por objeto os atributos físicos, psíquicos e morais da pessoa em si e em suas projeções sociais.".

Silvio Romero Beltrão (2005, p. 123) ainda define que esses direitos são uma categoria especial dos direitos subjetivos, fundados na dignidade da pessoa humana, garantindo o gozo e respeito ao próprio ser, em todas suas manifestações físicas ou psíquicas.

Constata-se que esses direitos detêm de uma conceituação que abrange todos os atributos do ser humano, acrescentando o fato de que a dignidade da pessoa humana é um fundamento a ser observado para com a tutela desses direitos.

Desta forma, chega-se a conceituar os direitos de personalidade como aqueles direitos inerentes à própria pessoa, vezes que portadora da dignidade em seu íntimo, trazendo a proteção 
a toda forma de pensamento, aspectos físicos e o respeito e resguardo frente à sociedade em que está inserida, não podendo ser violados.

Pelas características trazidas pela doutrina de Pablo Stolze Gagliano e Rodolfo Pamplona Filho (2014, p. 196) temos que os direitos de personalidade são "[...] a) absolutos; b) gerais; c) extrapatrimoniais; d) indisponíveis; e) imprescritíveis; f) impenhoráveis; g) vitalícios.".

Assim sendo, por absolutos entendemos que são aqueles direitos oponíveis contra todos e que todos tem de respeita-los, pelo simples fato de decorrer da dignidade da pessoa humana e, também, dada a sua vitaliciedade e generalidade, pois o ser humano, ao existir já é titular desses direitos e cessam, em regra, com a morte.

A critério de explicação há direitos de personalidade que podem ser violados mesmo com a ocorrência da morte de seu titular onde, no mais das vezes, se vislumbra quando a pessoa tem alguma lesão à sua honra ou imagem sem a devida autorização de seus herdeiros.

Na concepção de Silvio de Salvo Venosa (2008, p. 169) esses direitos são extrapatrimoniais “[...] porque inadmitem avaliação pecuniária, estando fora do patrimônio econômico. As indenizações que ataques a eles podem motivar, de índole moral, são substitutivo de um desconforto, mas não se equiparam à remuneração ou contraprestação.".

De forma correta a doutrina faz uma diferenciação entre reparação e a remuneração por alguma violação aos direitos de personalidade, haja vista que o objetivo de indenizações por dano moral, mormente ocorridas quando há uma inobservância aos direitos de personalidade, tentam restabelecer ao estado anterior que a pessoa estava, não monetizando o direito propriamente dito.

Sobre a indisponibilidade, cabe trazer o estabelecido por Pablo Stolze Gagliano e Rodolfo Pamplona Filho (2014, p. 196):

Preferimos utilizar a expressão genérica "indisponibilidade" dos direitos da personalidade, pelo fato de que ela abarca tanto a intransmissibilidade (impossibilidade de modificação subjetiva, gratuita ou onerosa - inalienabilidade) quanto à irrenunciabilidade (impossibilidade de reconhecimento jurídico da manifestação). A indisponibilidade significa que nem por vontade própria do indivíduo o direito pode mudar de titular [...]

É possível constatar que por indisponível o direito de personalidade acarreta na impossibilidade de mudança de sua titularidade, visto que inerente à própria pessoa, mesmo que de caráter oneroso ou gratuito e é irrenunciável, com impossibilidade de renunciar esse direito.

De todo modo, dada a sua importância e que o direito ora tutelado é reflexo da dignidade da pessoa humana, nada mais satisfatório do que declará-lo impenhorável e imprescritível, sendo que não pode ser suscetível de qualquer ato executório, dada sua indisponibilidade e intransmissibilidade, inerentes da dignidade e, também, pode ser reclamado a qualquer tempo, possibilitando que eventual violação seja rechaçada, independentemente de quando.

Por essas características e conceituações se vislumbra que os direitos de personalidade são oriundos da interpretação da dignidade da pessoa humana bem como suas características demonstram a importância e a tutela que é necessária para resguardar essa esfera de direitos.

\section{TITULARIDADE DOS DIREITOS DE PERSONALIDADE}

Tal como explanado alhures, a titularidade dos denominados direitos de personalidade é do ser humano, individualmente considerado, sendo que pelo simples fato de existir já se tem a concepção de que the é concedida essa gama de direitos.

Há, aqui, a concretização de que a pessoa natural é titular desse direito, abrangendo também o nascituro que, nas sábias palavras de Pablo Stolze Gagliano e Rodolfo Pamplona Filho (2014, p. 191) "[...] os nascituros, que, embora não tenham personalidade jurídica, têm seus 
direitos ressalvados, pela lei, desde a concepção, o que inclui, obviamente, os direitos da personalidade.".

Essa posição nos leva a crer que, como exposto em tópico anterior, o fundamento da República Federativa do Brasil, trazendo a dignidade da pessoa humana, os direitos de personalidade tem titulares irrestritos.

É o caso, também, das pessoas jurídicas, mesmo que não se tratem de pessoas naturais, possuidoras de vontade intrínseca, podem ser aplicadas algumas das características dos direitos de personalidade, vezes que sua vontade é realizada por meio de um representante que determinará como será realizada e pode ser alvo de violações aos direitos de personalidade.

Nesse prisma versa o artigo 52 do Código Civil ao dispor que "aplica-se às pessoas jurídicas, no que couber, a proteção dos direitos da personalidade", bem como a Súmula de n.o 227 do Superior Tribunal de Justiça ao preconizar que "a pessoa jurídica pode sofrer dano moral".

Desta maneira não há como deixar de crer que a pessoa jurídica é titular dos denominados direitos de personalidade, tanto é verdade que caso tenha uma violação à sua imagem, reputação, a indenização por dano moral é plenamente cabível, vislumbrando que pode ser sujeita de violações em sua esfera de direitos, mesmo que extrapatrimonial.

Por mais que sejam intransmissíveis esses direitos, quando não puderem ser exercidos pela pessoa originariamente titular, podem ser exercidos por quem os represente, como o caso dos menores de 16 (dezesseis) anos ou os assiste, no caso daqueles entre 16 (dezesseis) anos até a obtenção da maioridade aos 18 (dezoito) anos. Havendo, também, a possibilidade de que, quando falecer e houver alguma violação aos direitos de personalidade, sua proteção seja exercida pelos herdeiros.

\section{A (IR) RENUNCIABILIDADE DO DIREITO DE USO DE IMAGEM DO JOGADOR DE FUTEBOL}

Dentre as diversas formas de apresentação dos direitos de personalidade temos o direito de imagem como uma das esferas que mais se alastrou na casuística forense, haja vista que o avanço das redes sociais fez com que a imagem de cada um fosse exposta de forma mais rotineira e fácil, sem qualquer filtro posto.

Por imagem, Sílvio Romero Beltrão $(2005$, p. 123) leciona:

[...] Para o direito da personalidade, a imagem é entendida como a representação gráfica da figura humana, mediante procedimento de reprodução mecânica ou técnica. Juridicamente, é facultada exclusivamente à pessoa do interessado a difusão ou publicação de sua própria imagem e, com isso, também o seu direito de evitar sua reprodução, por se tratar de direito de personalidade.

A imagem, assim, é a reprodução da pessoa em si, seja por meio de retrato ou por meio de algum meio de difusão que diz sobre as características de seu exterior e, por se tratar de um direito de personalidade, somente o seu titular pode assentir quanto à sua exposição, ou para evita-la, podendo, se for o caso de ausente ou morto, transmitir aos herdeiros e demais representantes a defesa desses direitos.

Por essa concepção temos que o direito de imagem é inerente à condição humana, resguardando que o seu direito é de ter a possibilidade de reproduzi-la, se por terceiros, com autorização, e se não quiser não será posta ao público, vezes que há a exigência de concordância expressa de que seja divulgada.

O próprio Código Civil, a partir do artigo 20, já autoriza a cessão do uso do direito de imagem, ou seja, a renúncia, nesse caso, é do uso e não do direito propriamente dito, vezes que a pessoa não pode renunciar de um direito que é ínsito pela condição humana. 
No caso do direito desportivo, trazendo à baila o direito de imagem dos jogadores de futebol, temos que esses são alvo de diversas propagandas e produções publicitárias que expõem sua imagem de forma demasiada e, no mais das vezes, com a concordância desses na sua deflagração.

Destaca-se que, quando o próprio jogador aceita em ceder sua imagem para os veículos de telecomunicação, ele renuncia ao direito de personalidade relacionado ao seu uso, mesmo que se trate de uma irrenunciabilidade latente e destoante das características desses direitos.

Há a necessidade de que se tenha a diferenciação do que se entende por "direito de imagem" e "direito de arena" sendo que o primeiro é aquele individual, especificamente para o jogador e o segundo, conforme disposição de Aurélio Franco de Camargo (2018) "o direito de arena não está relacionado à veiculação da imagem individual do atleta, mas sim à exposição de sua imagem enquanto partícipe daquele determinado evento futebolístico".

De acordo com o artigo 42 da Lei n. 9 9.615/98 o direito de arena é destinado aos sindicatos e, após isso, repassado ao jogador, tendo em vista a utilização de sua imagem em algum evento, vinculando-o ao clube em que está contratado.

Com isso, admite-se no ordenamento jurídico pátrio a renúncia ao direito de uso do direito de imagem, devendo deixar claro no ato da contratação do jogador de que se trata de "direito de imagem" propriamente dito, e não relacionado às remunerações de origem trabalhista, que não se confundem.

Fábio Menezes de Sá Filho (2010, p. 93) adverte que somente não se constituirá salário se o direito de imagem for tratado como natureza civil, vezes que se desvirtuar-se do propósito original passa a ser reconhecida como de viés trabalhista.

A critério de explanação o contrato desportivo, tal como dos atletas de futebol, é um contrato de trabalho e, com isso, sujeito à competência da Justiça do Trabalho.

Sobre a sua sujeição à justiça especializada, Domingos Sávio Zainaghi (2003, p. 37):

O jogador de futebol é um trabalhador e sua relação jurídica é mantida com o clube; dessarte, quando tiver qualquer problema deve ser dirimido pela justiça do trabalho, conforme $\mathrm{CF} / 88$, art. 114 . Ao juiz do trabalho compete solucionar o litígio porque ele por formação e conhecimento jurídicos está voltado ao princípio de proteção ao trabalhador, porque a própria CLT, no art. 3ำ, parágrafo único, estabelece que não haverá distinção entre o trabalho intelectual, técnico ou manual.

Denota-se que o jogador de futebol, a qualquer fim, detém de vinculo empregatício com o clube, sendo que os direitos de imagem, pelo que já foi selecionado, versará não sobre suas atividades laborativas, mas com relação à sua imagem em si.

O direito de uso de imagem ao ser vinculado ao contrato de trabalho terá que ter uma divisão de sua utilidade de forma expressa e latente, tendo em vista as ações dos empregadores em tentar colocar todo e qualquer tipo de verba trabalhista como de direito de imagem para mascara-las, evitando o pagamento da carga tributária e laboral, nos mesmos termos do artigo 87A da Lei n.o 9.615/98 (Lei Pelé).

E caso o empregador assim o faça, pode ser alvo de anulação perante a Justiça do Trabalho, consoante entendimento firmado quando do julgamento dos Embargos no Recurso de Revista de n. 406-17.2012.5.09.0651, de relatoria do Ministro João Oreste Dalazen da Subseção I Especializada em Dissídios Individuais (SDI - 1) do Tribunal Superior do Trabalho, em notícia veiculada no sítio da Revista Consultor Jurídico.

Cabe observar, ainda, o preconizado por Pablo C. Barbieri (2012, p. 144-145):

La explotación comercial de la imagen personal de los deportistas - sobre todo con fines publicitarios - es un fenômeno incontrastable e indiscutible. Es más, muchas vecesm sus fichajes no solamente se llevan a cabo por sus calidades estrictamente profesionales, sino también por el impacto que ello provocará en la afición y la posibilidad de convertirlos en 
verdaderos "reclamos publicitarios", esto es, el atractivo que su contratación generará en posibles auspiciantes o sponsors. ${ }^{1}$

Da doutrina alienígena extraímos que jogadores como Neymar Jr. e Cristiano Ronaldo, pela grande exposição midiática que detém bem como o potencial de trazer novos patrocinadores e até torcedores, acrescendo às suas características futebolísticas a possibilidade de usar de sua imagem para que prospecte novas rendas e verbas aos clubes nos quais estiverem.

Evidentemente que com a prática mercantil da utilização da imagem poderá se chegar a indagar se esse direito pode ser monetizado, ainda a resposta é não, tendo em vista o mesmo pensamento aplicável à possibilidade de renunciar o uso da imagem, da mesma forma poderá se renunciar, e consequentemente quantificar, o valor referente ao uso, e não necessariamente ao direito de imagem do jogador de futebol.

Outrossim, ao estabelecer uma quantia pelo uso de direito de imagem, por ser de natureza cível referidas verbas, se delimitará como de forma indenizatória, ou seja, indenizando o próprio jogador do que estará se utilizando.

O cerne da questão cinge-se na indenização do que foi violado, tentando restabelecer o status quo ante do próprio titular do direito de imagem, mesmo que renuncie ao uso o que se protegerá sempre é o direito à própria imagem do atleta, o que deve ser alvo de restituição por meio monetário.

Muito embora possa parecer um enriquecimento ilícito por parte do atleta, vez que consentiu para utilização de sua imagem é certo que pela exposição que detém (ou terá) nada mais satisfatório do que seja indenizado por isso.

De forma contrária, Sílvio de Salvo Venosa (2008, p. 174) leciona que “[...] é preciso avaliar se, de fato, há abuso na divulgação da imagem. Nem sempre a simples divulgação de uma imagem é indevida [...]".

Em que pese o entendimento do ilustre doutrinador é certo que no caso dos jogadores de futebol, ainda mais em se tratando de uma área em que o direito de uso da imagem é comerciada e monetizada, toda e qualquer divulgação da pessoa do jogador deve ser precedida de sua autorização, pelo simples fato de que é negociado o seu valor relacionado à sua própria imagem, por meio de um contrato com as partes envolvidas, seja clube, seja patrocinador, podendo ocasionar prejuízos a terceiros.

Nesse trilhar, quando o próprio jogador estabelecer a possibilidade de que o uso da sua imagem pode ser utilizado, é significativo de que é renunciável o direito de fruição desse direito, sendo que não pode ser confundido com a natureza cível que essas verbas detêm, puramente de natureza indenizatória.

\section{CONCLUSÃO}

Com tudo o que foi exposto é forçoso concluir que a renuncia ao direito de uso de imagem é plenamente possível para os jogadores de futebol, sendo que o contrato relacionado a esse deve ter sua natureza cível, sob pena de se caracterizar um abuso e ilegalidade por parte do empregador, além do fato de que a remuneração do que foi pago pelo uso não se caracteriza uma monetização dos direitos de personalidade, detendo viés indenizatório.

Ademais, o atleta, pela grande exposição que detém nos jogos e programas publicitários necessita de um resguardo e consequente proteção do seu direito de imagem, tendo em vista a grande divulgação de suas características de forma fácil e ágil pelo simples avanço tecnológico, ou

\footnotetext{
${ }^{1}$ A exploração comercial da imagem pessoal dos atletas - especialmente para fins publicitários - é um fenômeno incontestável e indiscutível. Além disso, muitas vezes suas contratações não são realizadas apenas por suas qualidades estritamente profissionais, mas também pelo impacto que isso causará no hobby e a possibilidade de transformá-las em verdadeiras "reivindicações publicitárias", ou seja, a atratividade de suas contratações gerará em possíveis patrocinadores ou patrocinadores. (tradução nossa)
} 
pelas redes sociais ou pelos veículos conhecidos desde tempos anteriores (jornais, revistas, pôsteres, etc).

Portanto, a irrenunciabilidade é do direito de imagem, podendo o próprio jogador, caso assim queira e o faça expressamente, renunciar o direito de fruição desse para o clube, patrocinadores, com quem contratar, mesmo que perceba alguma quantia monetária sobre isso, vezes que de caráter indenizatório.

\section{REFERÊNCIAS}

BARBIERI, Pablo C. Derecho de imagen en el deporte. Buenos Aires: Ad-Hoc, 2012.

BELTRÃO, Silvio Romero. Direitos da personalidade: de acordo com o novo código civil. São Paulo: Atlas, 2005.

BRASIL. Constituição (1988). Constituição da República Federativa do Brasil. Disponível em: <http://www.planalto.gov.br/ccivil_03/constituicao/ConstituicaoCompilado.htm>. Acesso em: 09 ago. 2018.

BRASIL. Lei n. 9.615, de 24 de março de 1998. Institui normas gerais sobre desporto e dá outras providências. Disponível em: <http://www.planalto.gov.br/ccivil_03/Leis/L9615consol.htm>. Acesso em: 09 ago. 2018.

BRASIL. Lei n. 10.406, de 10 de janeiro de 2002. Institui o Código Civil. Disponível em: <http://www.planalto.gov.br/ccivil_03/leis/2002/l10406.htm>. Acesso em: 09 ago. 2018.

BRASIL. Superior Tribunal de Justiça. Segunda Seção. Súmula n. 227. A pessoa jurídica pode sofrer dano moral. Brasília, 08 de setembro de 1999. Disponível em: <http://www.stj.jus.br/docs_internet/VerbetesSTJ_asc.txt>. Acesso em: 09 ago. 2018.

CAMARGO, Aurélio Franco de. O direito de arena e direito de imagem do jogador futebol profissional. Disponível em: <http://emporiododireito.com.br/leitura/o-direito-de-arena-e-direitode-imagem-do-jogador-futebol-profissional>. Acesso em: 09 ago. 2018.

DIREITO de imagem não é integrado a salário de jogador de futebol, diz TST. Revista Consultor Jurídico. Disponível em: <https://www.conjur.com.br/2017-dez-07/direito-imagem-nao-integradosalario-jogador-futebol>. Acesso em: 09 ago. 2018.

GAGLIANO, Pablo Stolze; PAMPLONA FILHO, Rodolfo Mário. Novo curso de direito civil: volume 1 : parte geral. 16. ed., rev. e atual. São Paulo: Saraiva, 2014.

SÁ FILHO, Fábio Menezes de. Contrato de trabalho desportivo: revolução conceitual de atleta profissional de futebol. São Paulo: LTr, 2010.

SZANIAWSKI, Elimar. Direitos de personalidade e sua tutela. 2. ed., rev., atual. e ampl. São Paulo: Revista dos Tribunais, 2005.

VENOSA, Sílvio de Salvo. Direito civil: parte geral. 8. ed. São Paulo: Atlas, 2008. 
ZAINAGHI, Domingos Sávio. Contrato de Trabalho de Atleta Profissional. In AIDAR, Carlos Miguel. Curso de Direito Desportivo. São Paulo: Ícone, 2003. 